\title{
Ocular manifestations of HIV/AIDS: A literature review (Part 2)*
}

\author{
P Govendera, R Hansrajb, KS Naidoo ${ }^{c}$ and L Visser ${ }^{d}$
}

a, b, c Discipline of Optometry, School of Physiotherapy, Sport Science and Optometry, Faculty of Health Sciences, University of KwaZulu-Natal, Westville Campus, Private Bag X54001, Durban, 4000 South Africa

d Department of Ophthalmology, Nelson R Mandela School of Medicine, University of KwaZulu-Natal, Umbilo Road, Durban, 4000 South Africa

a, c International Center for Eyecare Education, 172 Umbilo Road, Durban, 4000 South Africa

c African Vision Research Institute, 172 Umbilo Road, Durban, 4000 South Africa

a $<$ govenderp@ukzn.ac.za $>$

Received 30 December 2010; revised version accepted 27 February 2011

This is the second part of an article on the review of published literature on the ocular manifestations of HIVIAIDS. This part deals with the posterior, orbital, neuro-ophthalmic and iatrogenic manifestations of the disease. (S Afr Optom 2011 70(2) 81-88)

\section{Introduction}

The posterior segment of the eye is predisposed to disorders that involve the retina, choroid and optic nerve in HIV infection. These disorders are broadly divided into two categories namely, those associated with non-infectious causes and those associated with infectious causes. Disorders associated with noninfectious causes include HIV-associated retinopathy and optic disc changes. Disorders associated with infectious causes include cytomegalovirus retinitis (CMVR), toxoplasmosis and other opportunistic infections. The majority of cases of retinal disease are seen in severely immune-compromised individuals, with CD4+ counts of less than or equal to ${ }^{1-3} 100$ cells $/ \mathrm{mm}^{3}$. The most commonly occurring posterior segment manifestations of HIV/AIDS are retinal microvasculopathy (non-infectious) and cytomegalovirus retinitis (infectious) ${ }^{4}$.

\section{Posterior segment ocular manifestations of HIV/ AIDS not associated with opportunistic infection}

\section{HIV retinopathy}

HIV retinopathy, also referred to as HIV-related ocular micro-angiopathic syndrome, is a non-infectious microvascular disorder characterised by cotton wool spots, microaneurysms, retinal haemorrhages, Roth spots, telangiectatic vascular changes and areas of capillary non-perfusion ${ }^{5,6}$. HIV retinopathy is one

\footnotetext{
a BOptom (UDW) CAS (NECO) MOptom (UKZN)

b BOptom (UDW) CAS (NECO) MOptom (UDW) PhD (UKZN)

${ }^{c}$ BSc BOptom (UDW) MPH (Temple) OD (PCO) PhD (UNSW)

d MBChB (Pret) MMED (Ophth) (Natal) FCOphth (SA)
}

*This paper is based on work by P Govender towards a Masters degree in the Discipline of Optometry of the University of KwaZulu-Natal with the supervision of Professor KS Naidoo and Drs R Hansraj and L Visser 
of the most common retinal manifestations of HIV and is found in $70 \%$ of persons with HIV/AIDS ${ }^{7,8}$. Research has suggested that altered blood flow may contribute to vascular damage and ocular ischaemic lesions in individuals with HIV infection? ${ }^{9}$. A study by Kuppermann et a ${ }^{10}$ showed that $45 \%$ of patients with a CD4+ count of less than or equal to 50 cells $/ \mathrm{mm}^{3}$ presented with HIV retinopathy indicating that HIV retinopathy is a late manifestation of AIDS.

\section{Cotton wool spots}

Cotton-wool spots (CWS) are the most common ocular micro-angiopathic manifestations of HIV/ AIDS, however, they are non-specific and may be seen in variety of conditions such as diabetes, hypertension, leukaemia, anaemia and systemic lupus erythematosis 6,11 . Faia et $a l^{12}$ has shown that the prevalence of HIV retinopathy is greater when the CD4+ cell count is lower than 100 cells $/ \mathrm{mm}^{3}$ while Lima $^{13}$ indicated that the CD4+ count can as low as below 50 cells $/ \mathrm{mm}^{3}$ in the presence of HIV retinopathy. Cotton wool spots (see Figure 1) are caused by a circulatory disturbance within tiny areas of the retina. The occlusion of pre-capillary arterioles is commonly located in the superficial retina ${ }^{7}, 13,14$. While HIV retinopathy may resemble the manifestations of diabetic and hypertensive retinopathy, it lacks the hard exudates that accompany the ocular manifestations of diabetes and hypertension. Cotton wool spots can be mistaken, due to their colour, for the infective lesions of cytomegalovirus retinitis (CMVR). Unlike these CMVR infective lesions CWS are transient, not visually-threatening, and tend to disappear within 6-12 weeks ${ }^{11}$. The presence of CWS suggests a microvascular alteration in AIDS that is probably related to the high levels of circulating immune complexes found in the condition ${ }^{15}$. Pepose et al ${ }^{16}$ further suggested that the deposition of immune complexes causes axoplasmic stasis, ischaemia and, consequently, CWS formation. While HIV retinopathy may resemble the manifestations of diabetic and hypertensive retinopathy, it lacks the hard exudates that accompany the ocular manifestations of diabetes and hypertension.



Figure 1. Cotton wool spots

(Photo courtesy of Dr Linda Visser)

\section{Retinal haemorrhages}

Retinal haemorrhages appear as flame-shaped areas when they affect the nerve fibre layer and as dot-and-blot patterns when they affect the deeper layers of the retina ${ }^{7,17}$. Retinal haemorrhages are seen less frequently than CWS and are estimated to occur in approximately $30 \%$ of persons with advanced HIV/AIDS ${ }^{12}$. The histopathological findings of retinal vessels resemble that of diabetic retinopathy, with pericyte necrosis, endothelial cell swelling and thickened basement membranes being a feature of the condition ${ }^{12}$. It is suggested that the vascular injury includes immunoglobulin deposition, direct infection of the endothelial cells with HIV and hyperviscosity due to increased red blood cell aggregation, fibrinogen and increased polymorphonuclear leukocyte rigidity ${ }^{12}$.

\section{Telangiectatic vascular changes}

Retinal telangiectasias are known as a group of rare, idiopathic anomalies of the retinal vasculature characterised by irregular dilation, microaneurysms and vessel failure and may be found in HIV-infected persons ${ }^{18,19}$.

\section{Manifestations due to opportunistic infections}

Individuals with advanced HIV/AIDS may be affected by a number of opportunistic infections of the retina and choroid. Cytomegalovirus retinitis is the most common retinal infection in individuals with HIV/AIDS 5 . 


\section{Cytomegalovirus retinitis}

Cytomegalovirus is the most common viral opportunistic infection in HIV/AIDS $1,20,21$. The clinical disease of CMV has been found in up to $40 \%$ of individuals with advanced HIV/AIDS 1 . Research $^{22}$ has shown that prior to the introduction of Highly Active Antiretroviral therapy (HAART), CMV was noted as a familiar cause of blindness and death in individuals with advanced HIV/AIDS in western countries. The virus is usually acquired in childhood and may remain latent for life ${ }^{22}$. CMV retinitis is the most common presentation of CMV in the body, although other infections of the gastrointestinal tract, lungs and neural disorders are also reported frequently $20,23,24$. It has been found 25 that despite the high prevalence of CMV antibody in HIV infection, the clinical manifestations of CMV disease do not generally present until the CD4+ count drops below $100 \mathrm{CD} 4+$ cells $/ \mathrm{mm}^{3}$. Some studies ${ }^{5,26-27}$ have indicated that the risk of occurrence increases with a CD4+ count as low as below 50 cells $/ \mathrm{mm}^{3}$ with the average CD4+ count ${ }^{12}$ at the time of diagnosis of CMV retinitis being 17 cells $/ \mathrm{mm}^{3}$.

Cytomegalovirus infection of the retina leads to viral invasion of retinal cells with resultant retinal necrosis. The clinical appearance of full thickness granular retinal necrosis areas appears as a whitish opacification of the retina with exudates and haemorrhages ${ }^{7,20}$. The appearance of these characteristic lesions depends on the location and rate of disease progression. CMV retinitis has therefore been classified into sight-threatening and nonsight-threatening 24 . Non-sight-threatening lesions are typically granular in appearance, begin in the periphery and tend to cause symptoms of flashes or floaters while sight-threatening lesions originate in the posterior pole and are more oedematous and fluffy in appearance ${ }^{24}$.

Cytomegalovirus necrosis can sometimes be confused with CWS, however, CMV lesions tend to enlarge and coalesce over time, forming large, wedge-shaped areas of involvement ${ }^{20}$ (Figure 2). Even though individuals complain of blurred vision, scotomas, light flashes, or floaters, approximately $15 \%$ of infected patients are often asymptomatic despite the presence of extensive or vision-threatening CMV retinitis ${ }^{12,20}$. Consequently, it is recommended ${ }^{12}$ that routine dilated fundus examination should be performed at intervals of three months on individuals with CD4+ cell counts of less than 50 cells $/ \mathrm{mm}^{3}$. Those patients who present with vision loss may have a profound loss that is irreversible and it may occur via three mechanisms, namely, direct damage to the macula and optic nerve, retinal detachment which may occur even after CMV retinitis has resolved and immune recovery uveitis ${ }^{22}$. These patients with resultant blindness would need constant assistance from another individual thereby creating a profound impact on the individual's independent existence and the family unit ${ }^{22}$.

The introduction of Highly Active Antiretrovial therapy (HAART) has been implicated in the rapid decline in CMV retinitis incidence and a modification of the clinical course ${ }^{12,23,24,26}$. Treatment of CMV is directed toward CMV disease and recovery of immune function due to HIV/AIDS. While antiretrovirals (ARVs) are continued indefinitely, the CMV specific medication is continued only until the immune restoration to a CD4+ cell count of at least 100 cells $/ \mathrm{mm}^{3}$ has been achieved ${ }^{22}$. Ganciclovir, foscarnet and cidofovir are all effective therapies, however, each has prominent toxicities $24,27$. Among the systemic toxic effects are neutropenia, thrombocytopenia, nephrotoxicity, while the ocular toxic reactions include uveitis, endophthalmitis, low intra-ocular pressure, intravitreal bleeding and early retinal detachment ${ }^{27}$. Chronic, daily, intravenous administration of ganciclovir and foscarnet has proven to be both risky and inconvenient and therefore alternative delivery systems have been devised. Ganciclovir is recommended for administration via oral and intravitreal implant routes while foscarnet is administered as an intravenous injection. This is accompanied byintermittentintravitrealadministration of cidofovir ${ }^{24}$. 


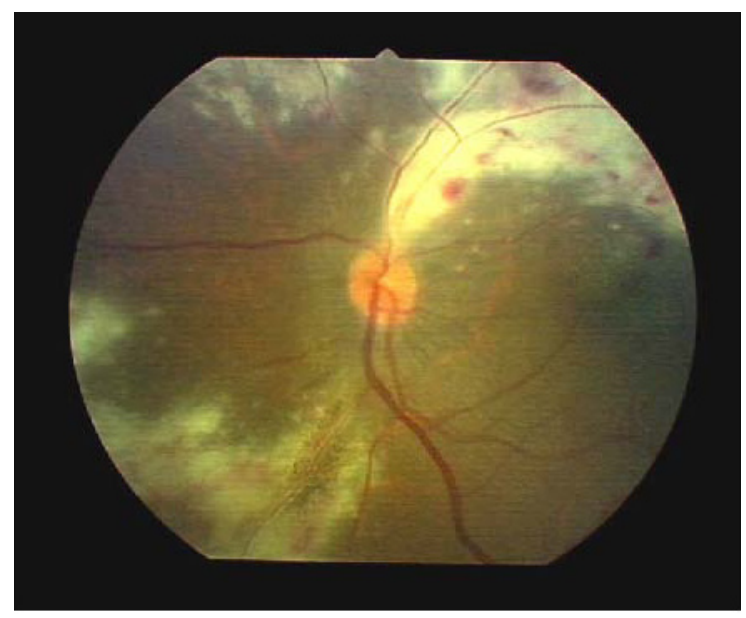

Figure 2 CMV retinitis

(Photo courtesy of Dr Linda Visser)

\section{Toxoplasma retinochoroiditis}

Toxoplasma gondii has been found to affect about $10 \%$ of HIV/AIDS patients ${ }^{7}$. The organism that causes toxoplasma retinochoroiditis has been found to be relatively rare and accounts for $1 \%$ of AIDSrelated retinal infections, however, its infectious prevalence is known to vary between geographic regions and populations ${ }^{13}$. The organism exists in three forms; sporozoites, bradyzoites and tachyzoites. Sporozoites or oocysts result from the parasite's sexual cycle that occurs in the cat intestine and are eliminated by the cat and undergo sporulation to become infectious. Bradyzoites are slowly multiplying organisms contained in tissue cysts and are localised to muscle and brain and may live in host cells for months to years and once these cysts are ingested, gastric enzymes of the host degrade the cyst wall and liberate them. Tachyzoites are rapidly dividing organisms which are found in the host tissues during the acute phase of infection and are responsible for tissue destruction in the host. Human infection results from ingesting food contaminated with oocysts or uncooked food containing bradyzoites. Once the host is infected, the tissue cysts can persist for life. In the presence of inadequate immunity, bradyzoites can produce lesions when they disintegrate in the form of the tachyzoites which continue to multiply, destroying excessive numbers of cells in various organs, especially the lungs and brain thus causing pneumonia and encephalitis ${ }^{28}$.

Infection presents as multifocal retinochoroiditis with less frequent vitritis than in immune-competent individuals ${ }^{5}$. While this form of retinitis can be confused with other forms, it can be differentiated by the presence of intense, "fluffy" areas of retinal whitening with accompanying vitritis, sometimes referred to by the analogy "headlights in the fog" with retinal whitening being the headlight and the fog being the overlying vitritis ${ }^{5,18}$. The appearance of toxoplasmosis retinitis in immune-compromised individuals is different as its manifestation is often bilateral, multifocal and not associated with chorioretinal scars ${ }^{29}$. Toxoplasmosis retinitis could be confused with CMV retinitis but can be differentiated because it presents with less haemorrhage and more iritis and vitritis ${ }^{29}$ (Figure 3).

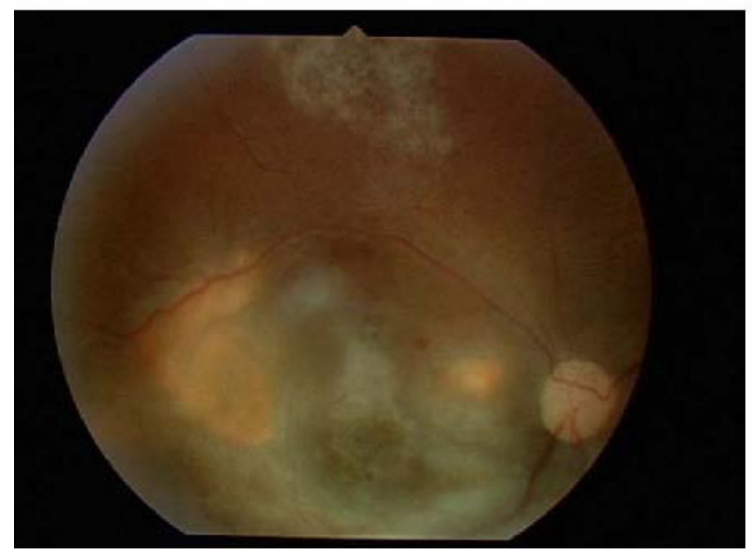

Figure 3 Active Toxoplasma chorioretinitis (Photo courtesy of Dr Linda Visser)

\section{Fungal retinitis}

The most common fungal organism implicated in fungal retinitis is candida while histoplasmosis and aspergillus infection tend/s to affect the choroid more often $^{12}$. Candida retinitis is commonly seen in HIVinfected patients (due to intravenous drug sources of infection) and is characterised by a fluffy white "mound" of retinal infiltrates, which may enlarge to involve the vitreous as well12,17.

\section{Bacterial retinitis}

Bacterial chorioretinitis occurs infrequently5 and is usually considered in patients with advanced HIV disease and posterior segment infection that is unresponsive to suspected viral, fungal or protozoan causes $^{5}$. Ocular syphilis is the most common intraocular bacterial infection 4,30 . Its resultant retinitis is found in $1 \%$ to $2 \%$ of patients who are HIV positive ${ }^{12}$. Infections present as a necrotic 
retina infiltrated with multiple histiocytes containing intracytoplasmic, encapsulated bacterial forms ${ }^{31}$. Other posterior segment manifestations of syphilis infection include retinal perivasculitis, intraretinal hemorrhage, papillitis, and panuveitis ${ }^{17}$.

\section{Cryptococcus chorioretinitis}

Cryptococcal ocular infection in immunesuppressed individuals is due to infection by yeast known as Cryptococcus neoforman ${ }^{1,5}$. Cryptococcus choroiditis is uncommon while its CNS involvement is more common $5,29,32$. Infection may also cause papilloedema which may be due to increased intracranial pressure from meningitis 5 . In addition, the associated abducens nerve palsy, headaches and papilloedema are the clinical signs that help differentiate cryptococcus choroiditis from other causes of multifocal choroiditis. There is usually a significant visual loss associated with the condition either due to optic neuropathy or cortical blindness ${ }^{29}$. The course of visual loss can range from profoundly rapid in hours if due to invasion and necrosis of the optic nerve tissue or slowly progressive of weeks to months if due to chronic papilloedema ${ }^{29}$.

\section{Pneumocystis choroiditis}

Pneumocystis carinii causes pneumonia in $80 \%$ of HIV/AIDS patients while its extra pulmonary dissemination is Pneumocystis carinii choroiditis? The choroidal infection is usually bilateral and multifocal, however, unifocal infection has been reported in certain instances ${ }^{17,33}$. Clinical lesions are distinctively slowly progressive multiple yellowish, well-demarcated, choroidal lesions in the posterior pole region of the fundus ${ }^{33}$. The lesions are referred to as "frothy vacuolar eosinophilic choroidal infiltrates which contain cystic and crescentic organisms"29. Loss of vision only ensues if there is involvement of the foveal area ${ }^{17}$.

\section{Acute retinal necrosis (ARN)}

Acute retinal necrosis is a progressive necrotic herpetic viral retinitis. It may occur due to involvement of varicella zoster virus (VZV), Herpes simplex virus (HSV) or CMV, however, VZV appears to be the most common causative $\operatorname{organism}^{5,17,34}$. It has been suggested that the presentation of ARN is similar in immune- competentand immune-compromised individuals ${ }^{35}$. It is commonly responsible for a severe bilateral loss of vision. Acute retinal necrosis is characterised by a peripheral retinal whitening that progresses to necrosis within several days ${ }^{5}$. Researchers ${ }^{34}$ have suggested that the pathophysiological mechanisms for causing ARN rest in the virulence of the virus after its reactivation. This virulence is particularly significant in immune-compromised patients in which case its severity is determined by the level of immuno-compromise ${ }^{34}$.

\section{Progressive outer retinal necrosis (PORN)}

Progressive outer retinal necrosis is a form of necrotising herpetic retinitis. While the VZV has been reported as the major etiological agent for PORN, HSV Type 1 has also be en implicated ${ }^{35}, 36$. It is most often bilateral in presentation and is characterised by severe visual loss, which can occur within weeks ${ }^{35}$. Progressive outer retinal necrosis is characterised by retinal lesions, which are often multiple, punctate white spots that coalesce (Figure 4). The exact pathophysiological mechanism is not currently clear, however, severe immune compromise and previous herpetic infection is necessary for presentation of the condition ${ }^{34}$. Risk factors for PORN include a low CD4+ cell count and recurrent, recent or current cutaneous, cerebral or visceral VZV or HSV infection ${ }^{34}$.

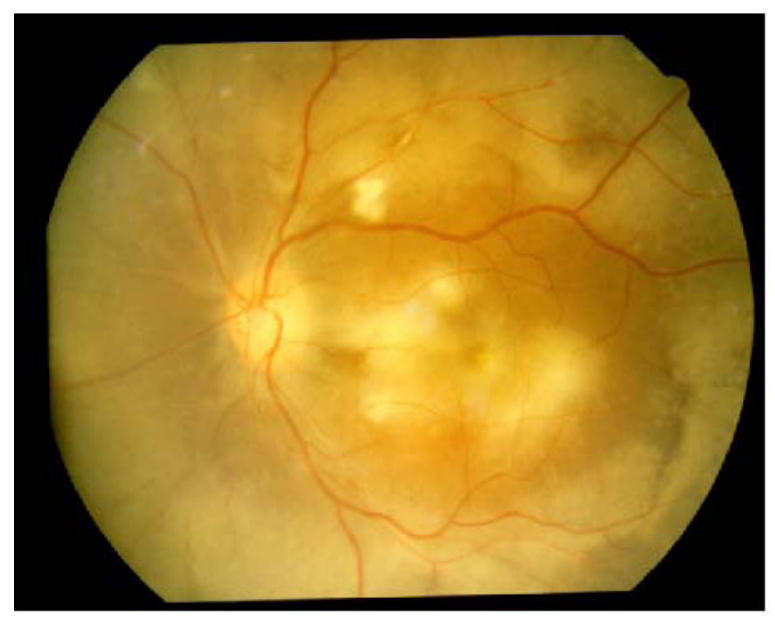

Figure 4 Progressive outer retinal necrosis

(Photo courtesy of Dr Linda Visser)

\section{Syphilitic retinitis}

Syphilis has been well documented in HIV infected individuals ${ }^{37,38}$. Ocular syphilis in HIV/AIDS includes 
iritis, vitritis, retrobulbar optic neuritis, perineuritis, papillitis, neuroretinitis, retinal vasculitis, necrotizing retinitis and exudative retinal detachment ${ }^{29}$. The clinical course of the disease has been found to be accelerated in patients with AIDS ${ }^{29}$. Visual loss is most frequently due to uveitis and secondarily due to optic nerve disease. Involvement can be either unilateral or bilateral and can involve the central nervous system (CNS) in up to $85 \%$ of cases $^{37,38}$. The infection in HIV positive individuals can run a more rapid and aggressive course than in non-immune-compromised individuals ${ }^{38}$.

\section{Ocular tuberculosis}

According to Havlir and Barnes ${ }^{39}$, tuberculosis (TB) is the most important HIV-related opportunistic infection in developing countries. Africa bears $29 \%$ of the global burden of TB and $34 \%$ of its related deaths ${ }^{40}$. The association between TB and HIV infection has been attributed to two processes, namely, people with latent TB acquire HIV infection which increases the risk of reactivation of the TB by a hundred-fold, or people with HIV infection acquire TB infections and their immune-suppression puts them at high risk of developing active $\mathrm{TB}^{40}$. Intensifying the $\mathrm{TB}$ crisis is the emergence of multi-drug resistant TB. In the province of KwaZulu Natal in South Africa, $50 \%$ of the cases of multi-drug resistant TB produced a mortality rate which exceeded $95 \%$. Virtually all structures of the eye can be affected by TB. The frequent ocular manifestation is granulomatous uveitis, which is usually accompanied by choroiditis ${ }^{41}$. Beare et a l $^{42}$ suggested that choroidal granuloma is not diagnostic of ocular TB, however, its presence can confirm its diagnosis in the presence of other signs.

\section{Orbital manifestations of HIV/AIDS}

Orbital manifestations of HIV infection include orbital cellulitis and orbital lymphoma and are noted in less than $1 \%$ of HIV/AIDS individuals ${ }^{4}$. Both of the aforementioned conditions are associated with aspergillus infection ${ }^{30}$, while Lima ${ }^{13}$ noted that other organisms including Rhizopus arrhizus, Toxoplasma gondii, and Pneumocystis carinii can also be implicated in the development of these conditions.

\section{Neuro-ophthalmic manifestations of HIV/AIDS}

Neuro-ophthalmic manifestations of HIV/AIDS have been related to infection or lymphoma of the brain and meninges and are found in $6 \%$ of AIDS patients $^{32}$. They may present at different stages of HIV infection ${ }^{43}$, however, Bhatia ${ }^{7}$ noted that involvement of the brain usually occurs in the final stages of HIV/ AIDS. Neuro-ophthalmic manifestations comprise of a variety of conditions which include optic nerve disease (oedema, inflammation, and atrophy), papilloedema due to raised intracranial pressure, retrobulbar neuritis, cortical blindness, pupillary defects, cranial nerve palsies, ocular motility disorders and visual field defects ${ }^{30,43}$. Most of these conditions are caused by infective lesions of the $\mathrm{CNS}^{43}$. Nerve palsies are associated with cryptococcal meningitis and intracellular toxoplasma cysts ${ }^{13}$. The most common infection is cerebral toxoplasmosis since Toxoplasma gondii seems to have a predilection to the central nervous system 4,43 . Symptoms include headache, fever, lethargy and seizures ${ }^{4}$. Moraes ${ }^{4}$ reported that neurological involvement might occur independently of ocular manifestations and vice versa. A study by Guiloff ${ }^{44}$ suggested that of those patients who present with neuro-ophthalmic manifestations of HIV/AIDS, $40 \%$ are due to opportunistic infection. Optic neuropathies in HIV patients may be attributed to compression, infiltration, infection, vaso-occlusion and inflammation ${ }^{13}$. Optic neuropathy has also been attributed to direct HIV infection ${ }^{43}$.

\section{Iatrogenic/post-treatment manifestations of HIV/ AIDS}

\section{Immune recovery uveitis (IRU)}

Immune Recovery Uveitis is defined as "new inflammation in an eye with controlled CMV retinitis or other opportunistic infection, not attributable to an alternative cause, following substantial recovery of immunity" by Otiti-Sengeri et al ${ }^{45}$. This condition has emerged in patients where the increase in white blood cells brought about by immune recovery respond to pre-existing CMV infection ${ }^{46}$. It is most frequent in patients with CMV retinitis who initiate HAART ${ }^{45}$. In addition to immune recovery, a very low CD4+ 
cell count at the time of initiation of HAART is also a significant risk factor for IRU together with HLA-8-18 as a genetic risk factor ${ }^{45}$. Manifestations of IRU include cataract, vitritis, macula oedema, optic disc oedema and epiretinal membrane ${ }^{47}$. These manifestations were further expanded in a comprehensive study conducted by Karavellas et al ${ }^{48}$ whose data suggested that "immune recovery vitritis or immune recovery uveitis is a chronic intraocular inflammatory syndrome, the clinical spectrum of which includes vitritis, papillitis, cystoid macula oedema, epiretinal membrane, vitreous haemorrhage, retinal neovascularisation and posterior vitreous detachment".

\section{Stevens-Johnson syndrome (SJS)}

According to Parillo and Parillo49, "SJS is an immunecomplex-mediated hypersensitivity disorder". It has been associated with four aetiologic categories, which include infectious, drug-induced, malignancy related and idiopathic. In patients with HIV/AIDS, SJS has been linked with viral and drug-induced etiologies ${ }^{49,50}$. The syndrome is one that affects the skin and mucous membrane ${ }^{51}$. The hypersensitivity reaction results in cell death which in turn results in a separation of the epidermis from the dermis ${ }^{49}$. Vision loss accompanying the disease occurs as a result of decreased tear production and forniceal foreshortening with trichiasis.

\section{Conclusion}

The vast range of ocular manifestations of HIV/ AIDS and the varying stages of disease at which the conditions may present make it imperative for the comprehensive management of the HIV/AIDS patient. A comprehensive ocular examination with special emphasis on ocular health should be conducted and should include a thorough case history, taking into account the duration of disease and disease progression as indicated by CD4+ cell counts; slit lamp biomicroscopy and dilated funduscopy. The comprehensive examination becomes mandatory especially since a large majority of patients with HIV/AIDS are visually asymptomatic ${ }^{52}$. In addition, the adherence to universal precautions with respect

\section{References}

1. Shukla DS, Rathinam SR, Cunningham ET. Contribution of HIV/AIDS Global Blindness. Int Ophthalmol Clin 2007 $4727-43$.

2. Sowka JW, Gurwood AS, Kabat AG. Handbook of Ocular Disease Management. [Online] Available from: http:// www.revoptom.com/cmsdocuments/2009/9/ro0409 handbook.pdf. 2009. Date accessed: 06/2008.

3. Wilson PL, Lipman MC, Gluck TA, Wilson W. Illustrated Handbook of Ocular Disease in HIV Infection. New York: Pathenon Publishing Company, 1999.

4. Moraes HV. Ocular manifestations of HIV/AIDS. Curr Opin Ophthalmol 200213 397-403.

5. Suresh K. Ophthalmic manifestations of HIV infection. Ind J Prac Doc 200631 2006-08-2006-09. [Online] Available from: http://www.indmedica.com/journals.php?journ alid=3\&issueid $=84 \&$ articleid $=1145 \&$ action $=$ article Date accessed: 07/2008.

6. Geier SA, Hammel G, Bogner JR, Kronawitter U, Berninger T, Goebel FD. HIV-related ocular microangiopathic syndrome and colour contrast sensitivity. Invest Ophthalmol Vis Sci 199435 3011-3021.

7. Bhatia RS. Ophthalmic manifestations of AIDS. J Ind Acad Clin Med 20023 85-88.

8. Jabs DA. AIDS Retinopathy: findings and significance. Ophthalmol Clin Nor Am 19981101.

9. Tufail A, Meiselman HJ, Engstrom RE, Hardy JRWD, Holland G, Holland N. Hemorheologic abnormalities and ophthalmic disease in patients with human immunodeficiency virus infection. Biorheology 199532 336-336.

10. Kuppermann BD, Petty JG, Richman DD, Mathews WC, Fullerton SC, Rickman LS, Freeman WR. Correlation between CD4 counts and prevalence of cytomegalovirus retinitis and human immunodeficiency virus-related noninfectious retinal vasculopathy in patients with acquired immunodeficiency syndrome. Am J Ophthalmol 1993115 575-582.

11. Verma N, Kearney J. Ocular manifestations of AIDS. Pap New Guin Med J 199639 196-199.

12. Faia LJ, Bakri S, DooHo BK, Nader M. HIV. Emedicine website. [Online] Available from: http://www.emedicine. com/OPH/topic417.htm. 2007. Date accessed: 08/2008.

13. Lima BR. Ophthalmic Manifestations of HIV infection. Digit J Ophthalmol [Online] Available from: http://www.djo.harvard.edu/print.php?url=/physicians/oa/ 674\&print $=1$. 2004. Date accessed: 04/2005.

14. Friedman AH. The retinal lesions of the acquired immune deficiency syndrome. Trans Am Ophthalmol Soc 198482 447-491.

15. Holland GN, Gottlieb MS, Yee RD, Schanker HM, Pettit TH. Ocular disorders associated with a new severe acquired cellular immunodeficiency syndrome. Am J Ophthalmol 198293 393-402.

16. Pepose JS, Holland GN, Nestor MS, Cochran AJ, Foos RY. Acquired immune deficiency syndrome. Pathogenic mechanisms of ocular disease. Ophthalmology 198592 472-484. 
17. Ahmed I, Ai E, Luckie A. Ophthalmic manifestations of HIV. HIV InSite Knowledge Base Chapter. [Online] Available from: http:/hivinsite.ucsf.edu. 2005. Date accessed: 03/2006.

18. Kanski JJ. Clinical Ophthalmology: A Systemic Approach. 3rd Edition. Oxford: Butterworth-Heinemann, 1994.

19. Dos Santos Motta MM, Coblentz J. Unilateral parafoveal retinal telangiectasis. Rev Brasil de Oftalmol 200766341 344.

20. Cheung TW, Teich SA. Cytomegalovirus infection in patients with HIV infection. Mount Sin J Med $199966113-$ 124.

21. Jabs DA. Ocular manifestations of HIV infection. Trans Am Ophthalmol Soc 199593 623-683.

22. Heiden D, Ford N, Wilson D, Rodrigues WR, Margolis T, Janseens B, Bedelu M, Tun N, Goemaere E, Saranchuk P, Sabapathy K, Smithuis F, Luyirika E, Drew WL. Cytomegalovirus Retinitis: The neglected disease of the AIDS pandemic. Pub Lib Sci J 20074 1845-1851.

23. Rauz S, Murray PI. Changing patterns of HIV related ocular disease. Sex Trans Infect 199975 18-20.

24. Ives DV. Cytomegalovirus disease in AIDS: Editorial Review. AIDS 199711 1791-1797.

25. Salzberger B, Hartmann P, Hanses F, Uyanik B, Comely OA, Wöhrmann A, Fätkenheuer G. Incidence and prognosis of CMV disease in HIV-infected patients before and after introduction of combination antiretroviral therapy. Infection 200533 345-349.

26. Palella FJ, Delaney KM, Moorman AC, Loveless MO, Fuhrer J, Satten GA, Aschman DJ, Holmberg SD. Declining morbidity and mortality among patients with advanced human immunodeficiency virus infection. New Eng J Med 1998338 853-860.

27. Jacobson MA. Treatment of Cytomegalovirus Retinitis in Patients with the Acquired Immunodeficiency Syndrome. New Eng J Med 19973371019.

28. Frenkel JK. Pathophysiology of toxoplasmosis. Parasitol Today 19884 273-278.

29. Vrabec TR. Posterior segment manifestations of HIV/ AIDS. Surv Ophthalmol 200449 131-157.

30. Cunningham ET, Margolis TP. Ocular manifestations of HIV infection. New Eng J Med 1998339 236-244.

31. Davis JL, Nussenblatt RB, Bachman DM, Chan CC, Palestine AG. Endogenous bacterial retinitis in AIDS. Am J Ophthalmol 1989107 613-623.

32. Banker AS. Posterior segment manifestation of human immunodeficiency virus/Acquired immune deficiency syndrome. Ind J Ophthalmol 200856 377-383.

33. Foster RE, Lowder CY, Meisler DM, Huang SS, Longworth DL. Presumed pneumocystis carinii choroiditis. Unifocal presentation, regression with intravenous pentamidine and choroiditis recurrence. In Vrabec TR. Posterior segment manifestations of HIV/AIDS. Sur Ophthalmol 200449 131-157.

34. Copeland R, Phillpotts BA. Ocular manifestations of HIV. EMedicine Website. [Online] Available from: www.emedicine.com/OPH/topic261.htm. 2009. Date accessed: 04/ 2005.
35. Kestelyn PG, Cunningham ET. HIV/AIDS and Blindness. Bull World Health Org 200179 208-213.

36. Kashiwase M, Sata T, Yamauchi Y, Minoda H, Usui N, Iwasaki T, Usui M. Progressive outer retinal necrosis caused by herpes simplex virus type 1 in a patient with acquired immunodeficiency syndrome. Ophthalmology 2000107 790-794.

37. Levy JH, Liss RA, Maguire AM. Neurosyphilis and ocular syphilis in patients with concurrent human immunodeficiency virus infection. Retina 19899 175-180.

38. Becerra LI, Ksiazek SM, Savino PJ, Marcus DK, Buckley RM, Sergott RC, Bosley TM. Syphilitic uveitis in human immunodeficiency virus-infected and non-infected patients. Ophthalmology 198996 1727-1730.

39. Havlir DV, Barnes PF. Tuberculosis in patients with human immunodeficiency virus infection. New Eng J Med 1999340 367-373.

40. Chaisson RE, Martinson NA. Tuberculosis in Africa Combating an HIV-Driven Crisis. New Eng J Med 2008 11 1089-1092.

41. Cunningham ET, Rathinam S. TB or not TB?: The perennial question. Editorial. Br J Ophthalmol 200185 127128.

42. Beare NAV, Kublin JG, Lewis DK, Schijffelen MJ, Peters RPH, Joaki JK, Zijlstra EE. Ocular disease in patients with tuberculosis and HIV presenting with fever in Africa. $\mathrm{Br} \mathrm{J}$ Ophthalmol 200286 1076-1079.

43. Wadood AC, Dhillon B, McLlwaine G, Brettle RP. Delayed diagnosis of HIV infection in ophthalmic practice. Eye 200418 293-298.

44. Guiloff RJ. AIDS: Neurological opportunistic infection in Central London. J Roy Soc Med 198982 278-280.

45. Otiti-Sengeri J, Meenken C, van den Horn GJ, Kempen JH. Ocular immune reconstitution inflammatory syndromes: Immune restoration disease. Curr Opin HIV \& AIDS 2008 3 432-437.

46. Roels P. Ocular manifestations of AIDS: New considerations for patients using highly active anti-retroviral therapy (HAART). Optometry 200475 624-628.

47. Robinson MR, Ross ML, Whitcup SM. Ocular manifestations of HIV infection. Curr Opin Ophthalmol 199910 431-437.

49. Karavellas MP, Azen SP, MacDonald JC, Shufelf CL, Lowder CY, Plummer DJ, Glasgow B, Torriani FJ, Freeman WR. Immune recovery vitritis and uveitis in AIDS: Clinical predictors, sequelae and treatment outcomes. Retina 200121 1-9.

49. Parillo SJ, Parillo CV. Steven-Johnson Syndrome. Emedicine website. [Online] Available from: http://emedicine. medscape.com/article/756523-overview. 2008. Date accessed: 05/2009.

50. Warren KJ, Boxwell DE, Kim NY, Drolet BA. Nevirapineassociated Stevens-Johnson syndrome. The Lancet 1998 351: 561 .

51. Coster DJ. Stevens-Johnson syndrome. Dev Ophthalmol 199728 24-31.

52. Biswas J, Sudharshan S. Anterior segment manifestations of human immunodeficiency virus/Acquired immune deficiency syndrome. Ind J Ophthalmol 200856 363-375. 